\title{
Development Permeability prediction for Bai Hassan Cretaceous Carbonate Reservoir
}

\author{
Tariq Kaka Rash', Qays Mohammed Sadeq ${ }^{2}$ \\ ${ }^{1}$ Department of Law and political science, University of Human Development, Sulaymania, Iraq, ${ }^{2}$ Department of \\ petroleum Geoscience, Universiti Teknologi Petronas, Seri Iskandar, Malaysia
}

\section{A B S T R A C T}

Permeability and porosity are the most difficult parameters to estimate in the oil reservoir because they are varying significantly over the reservoir, especially in the carbonate formation. Porosity and permeability can only be sampled at the well location. However, porosity is easy to estimate directly from well log data, permeability is not. In addition, permeability measurements from core samples are very expensive. Carbonate reservoirs are very difficult to characterize because of their tendency to be tight and heterogeneous due to deposition and diagenetic processes. Therefore, many engineers and geologists try to establish methods to get the best characterization for the carbonate reservoir. In this study, available routine core data from three wells are used to develop permeability model based on hydraulic flow unit method (HFUM) (ROI/FZI) for cretaceous carbonate middle reservoirs of Bai Hassan oil field. The results show that the HFUM is work perfectly to characterize and predict permeability for uncored wells because $R^{2} \geq 0.9$. It is indicating that permeability can be accurately predicted from porosity if rock type is known.

Index Terms: Carbonate Reservoir, Core Data, Dykstra-Parsons Coefficient (VK), Hydraulic Flow Unit Method (ROI/ FZI), Permeability, Porosity, Winland Method

\section{INTRODUCTION}

Permeability is one of the most important and critical petrophysical properties to determine the economic value of a reservoir. Prediction of permeability serves as a platform and prerequisite for any integrated reservoir studies. Single-phase permeability measurements are important to understand fluid flow through porous media. Permeability can be estimated indirectly using log data directly with core sample. Engineers and geologists observed that there is not a specifically defined trend line between porosity and permeability. In addition, their relationship is qualitative and

\begin{tabular}{|l|l|}
\hline \multicolumn{2}{|c|}{ Access this article online } \\
\hline DOI: 10.21928/uhdjst.v2n1y2018.pp8-18 & $\begin{array}{l}\text { E-ISSN: 2521-4217 } \\
\text { P-ISSN: 2521-4209 }\end{array}$ \\
\hline
\end{tabular}

Copyright (C) 2018 Rash and Sadeq This is an open access article distributed under the Creative Commons Attribution Non-Commercial No Derivatives License 4.0 (CC BY-NC-ND 4.0) is not direct or indirect in any way because it is possible to be high porosity without permeability as in clay and shale, Qays [1]. In addition, it is true to be high permeability with low porosity as in microfractured carbonates. However, there often can be found a very useful correlation between them, Tiab and Donaldson [2].

Kozeny [3] proposed the first empirical equation relating measurable rock properties with permeability using bundle of straight capillary tubes model with constant and uniform surface area. Carman [4] modified Kozeny equation by describing permeability in packs of uniformly sized spheres. Timur [5] proposed a generalized equation based on the work of Kozeny [3].

Amaefule et al. [6] introduced a new practically and theoretically based technique, which has been developed to identify and characterize units with similar pore throat geometrical attributes (hydraulic units). This theory of

Corresponding author's e-mail: Tariq Kaka Rash, Department of Law and political science , University of Human Development, Sulaymania, Iraq. E-mail: tareq.kakarash@uhd.edu.iq / qase1967@yahoo.com

Received: 18-01-2018

Accepted: 15-04-2018

Published: 25-05-2018 
hydraulic flow units (HFUs) and reservoir quality index pending the pore-throat, pore and grain arrangement and different macroscopic parameters.

\section{FIELD DESCRIPTION}

Bai Hassan field (Fig. 1) is located in the north of Iraq to the northwest of Kirkuk governorate and to the north of Kirkuk giant oil field. It is elongated from the north-west to the south-east; the surface structure differs from the subsurface structures because of the faults effect. The field is of a very complex nature with several main opposite faults and mini faults spreading in the field. It is $40 \mathrm{~km}$ in length and $3.8 \mathrm{~km}$ in width, it was discovered in 1929 and the production started on 1959, Sadeq [7].

\section{DYKSTRA-PARSONS COEFFICIENT VK}

Dykstra and Parsons used the log-normal distribution of permeability to define the coefficient of permeability variation, Tiab and Donaldson [2].

$V_{k}=\frac{S}{K}$
$K=\sqrt{\frac{\sum\left(K_{i}-K^{-}\right)^{2}}{n}}$

$\mathrm{S}$ is the standard deviation for permeability, $\mathrm{n}$ is a number of samples, $\mathrm{K}$ and $\mathrm{K}^{-}$are the permeability, and mean $K i$ is the permeability of main direction.

The range of this index is $0<V_{K}<1$ as and can be interpreted as follows:

1. If $V_{K}=0$, the reservoir is ideal homogeneous

2. If $0<V_{K}<0.25$, then the reservoir is slightly heterogeneous

3. If $0.25<V_{K}<0.50$, the reservoir is heterogeneous

4. If $0.50<V_{K}<0.75$, the reservoir is very heterogeneous

5. If $0.75<V_{K}<1$, the reservoir is extremely heterogeneous, and

6. If $V_{K}=1$, then the reservoir is perfectly heterogeneous, Tiab and Donaldson [2].

Hence, for Bai Hassan cretaceous middle carbonate reservoir, $\mathrm{V}_{\mathrm{K}}=11.4 / 12.59=0.9$. This value of DykstraParsons coefficient shows that the reservoir is extremely heterogeneous because it is a fractured carbonate reservoir.

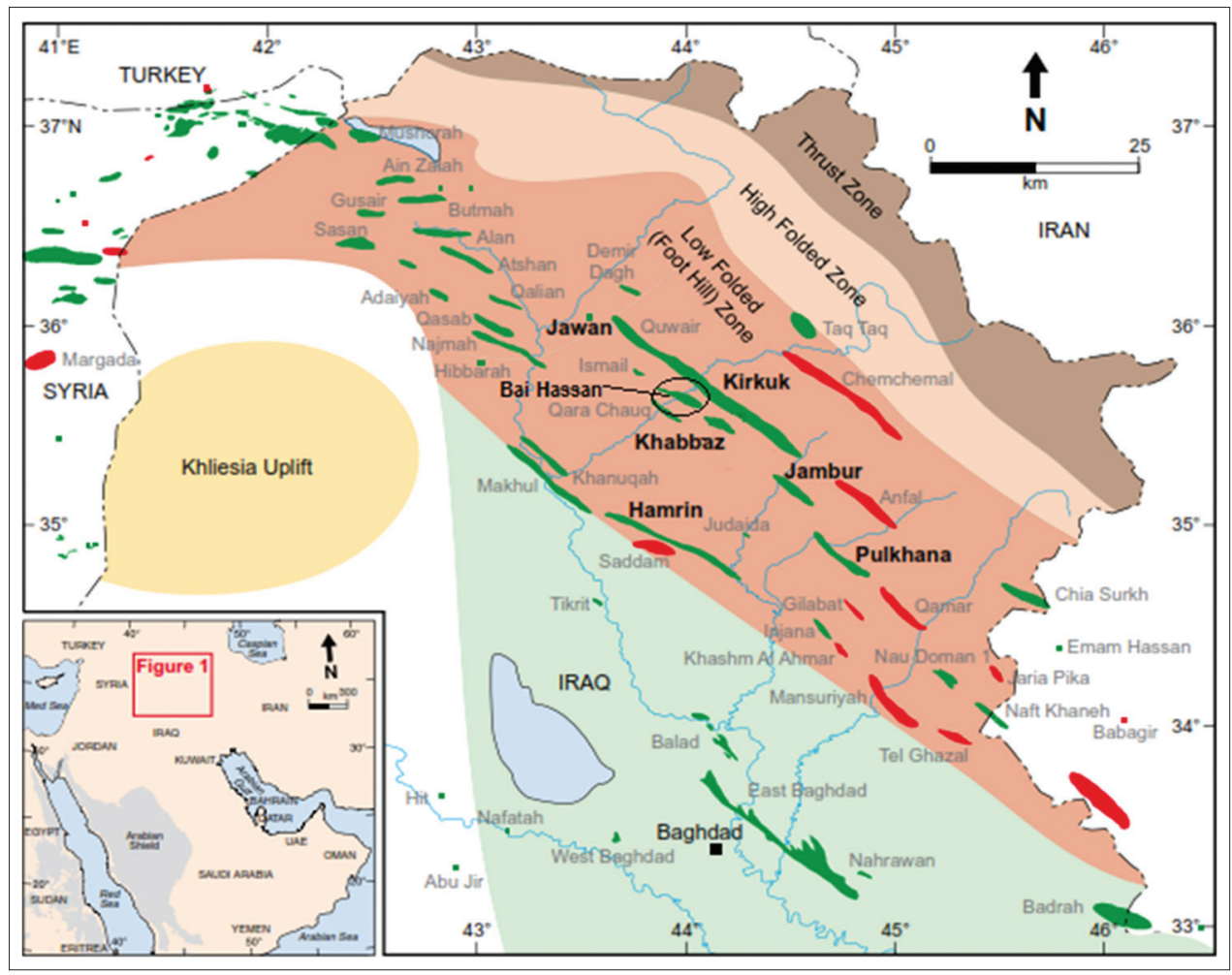

Fig. 1. The location of studied Bai Hassan field, Sadeq and Bhattacharya [8]. 


\section{PERMEABILITY PREDICTION DEPENDING ON ROCK TYPE METHODS}

\section{A. Conventional Method}

Conventional method for rock typing is based on simple regression evaluating permeability from log-derived porosity. In most cases, a linear relationship between log permeability and porosity is obtained, but in carbonate formations, it does not close to the actual case. Fig. 2 shows the conventional permeability-porosity relationship for the entire reservoir. There is a poor relationship between permeability and porosity $\left(R^{2}=0.191\right)$.

\section{B. Winland Method}

In this approach, a mathematical relationship introduced between the petrophysical properties such as porosity, permeability, and capillary pressure to pore-throat radius measured in a mercury injection capillary pressure experiment at mercury saturation of $35 \%$, Gunter et al. [9]. The Winland equation is:

$\log \left(R_{35}\right)=0.732+0.588 \log (\mathrm{k})-0.864 \log (\varnothing)$

Where, $\mathrm{R}_{35}$ is the calculated pore-throat radius at 35\% mercury saturation from mercury injection capillary pressure test, $\mathrm{k}$ is permeability (md), and $\varnothing$ is porosity (percentage). The core samples of similar $R_{35}$ values represent a single rock type. Petrophysical units can be defined using below classification of $R_{35}$ values:-

1. Megaport: When the value of $\mathrm{R} 35$ is $>10 \mu$

2. Macroport: When the value of R35 is between 2 and $10 \mu$

3. Mesoport: When the value of $\mathrm{R} 35$ is between 0.5 and $2 \mu$

4. Microport: When the value of R35 is between 0.1 and $0.5 \mu$.

Figs. 3-5 show the conventional permeability-porosity relationship for well $\mathrm{A}$, well $\mathrm{B}$, and well $\mathrm{C}$ depending on Winland method. As shown in these figures, there are weak relationships between permeability and porosity $\left(R^{2} \leq 0.19\right)$. Winland method is experimental measurements, which means that it does not work for all circumstances.

The inverse (negative) relationship between the porosity and permeability in this well resulted from the high shale volume (Vsh).

\section{HFU METHOD (HFUM)}

Geologists and engineers specified the definition of units to shape the description of reservoir zones as storage containers and reservoir conduits for fluid flow. Literatures confirmed

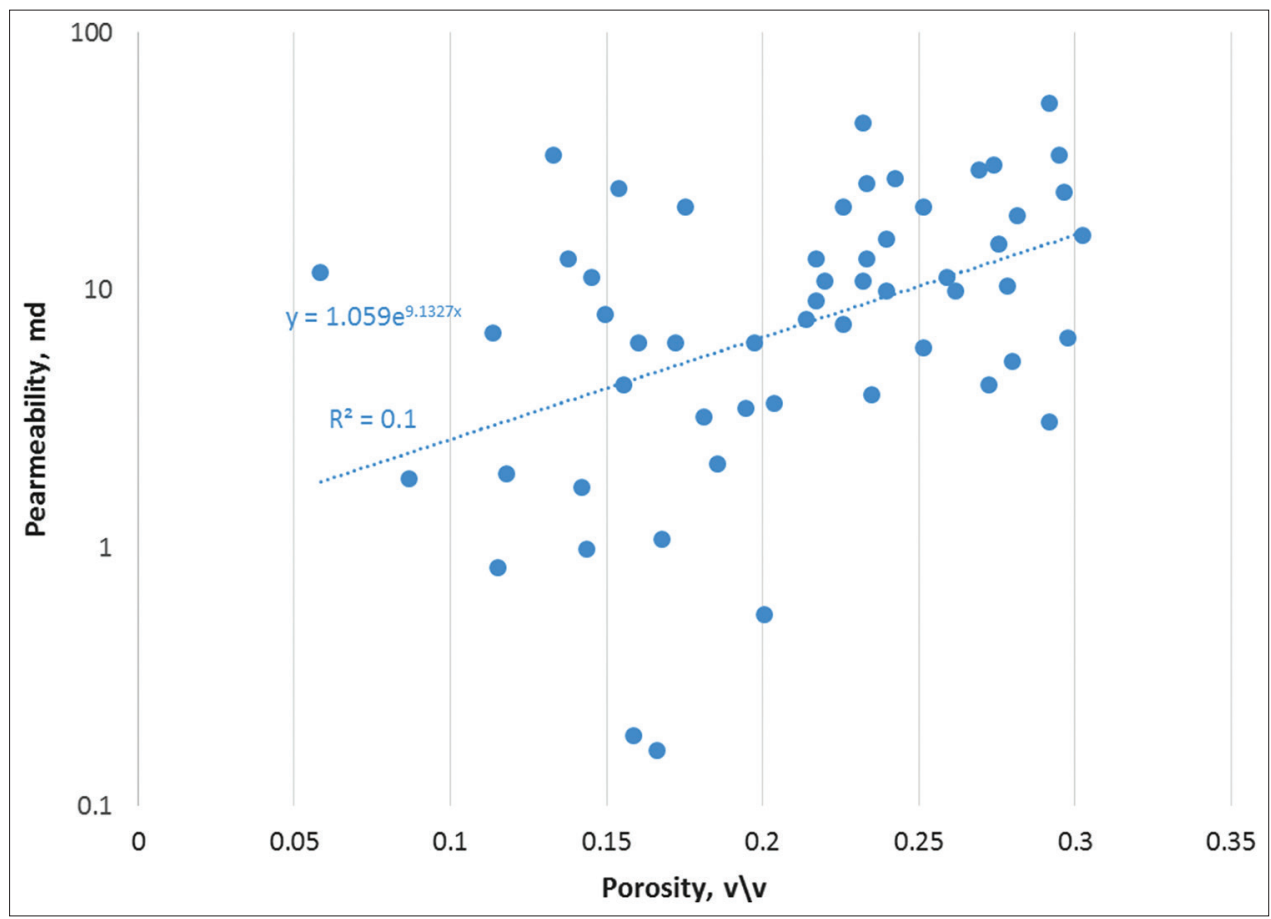

Fig. 2. Permeability porosity cross-plot for the entire reservoir 
Tariq Kaka Rash and Qays Mohammed Sadeq: Development Permeability prediction for Bai Hassan Cretaceous Carbonate Reservoir

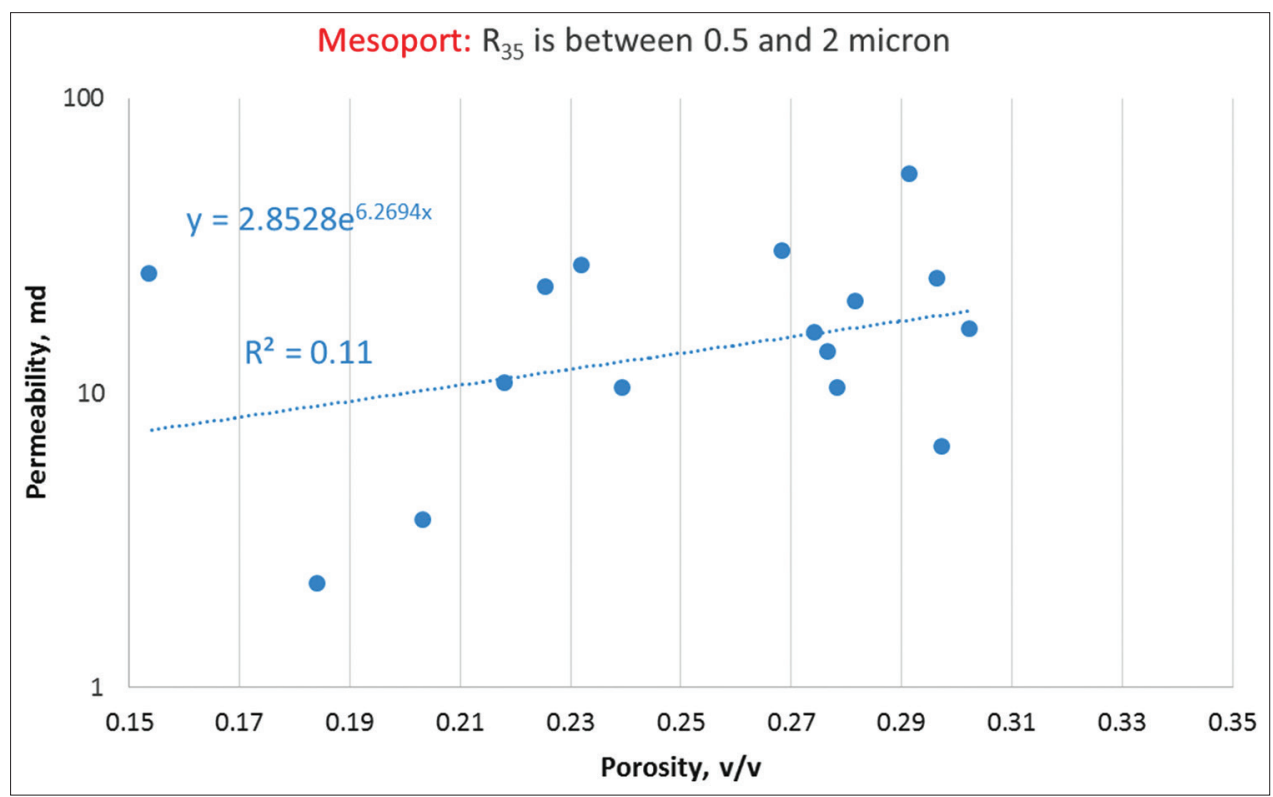

Fig. 3. Winland plot between porosity and permeability for well $A$

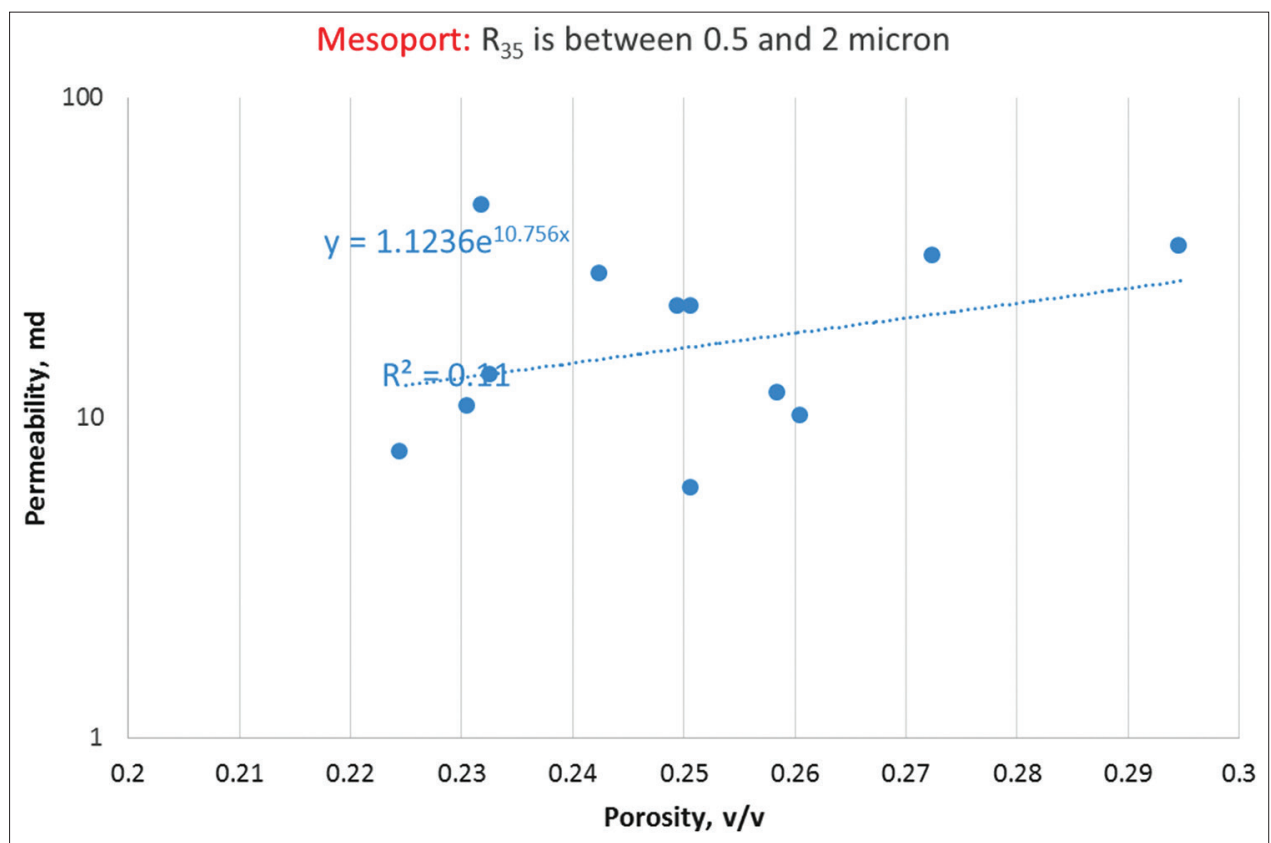

Fig. 4. Winland plot between porosity and permeability for well B

that the flow units, as the resultant of the depositional environment and diagenetic process. The hydraulic (pore geometrical) unit is the representative elementary volume of the total reservoir rock within the geological and petrophysical properties of the rock volume, Bear [10].
HFUs consider as map-able portion of the reservoir within which the geological and petrophysical properties that affect the flow of fluid are consistent and predictably different from the properties of other reservoir rock volume, Ebanks Jr. [11]. 
Hearn et al. [12] defined flow unit as a reservoir zone that is laterally and vertically has similar permeability, porosity, and bedding characteristic. A continuous stratigraphically interval of similar reservoir processes that honor the geologic framework and maintains the characteristic of the rock type, Gunter et al. [9]. The rock types are classified according to the following equations:

$$
\begin{aligned}
& \log \left(R_{35}\right)=0.732+0.588 \log (\mathrm{k})-0.864 \log (\varnothing) \\
& \log \left(\mathrm{R}_{35}\right)=0.732+0.588 \log (\mathrm{k})-0.864 \log (\varnothing) \\
& F Z I=\frac{Q R I}{\varnothing_{z}}
\end{aligned}
$$

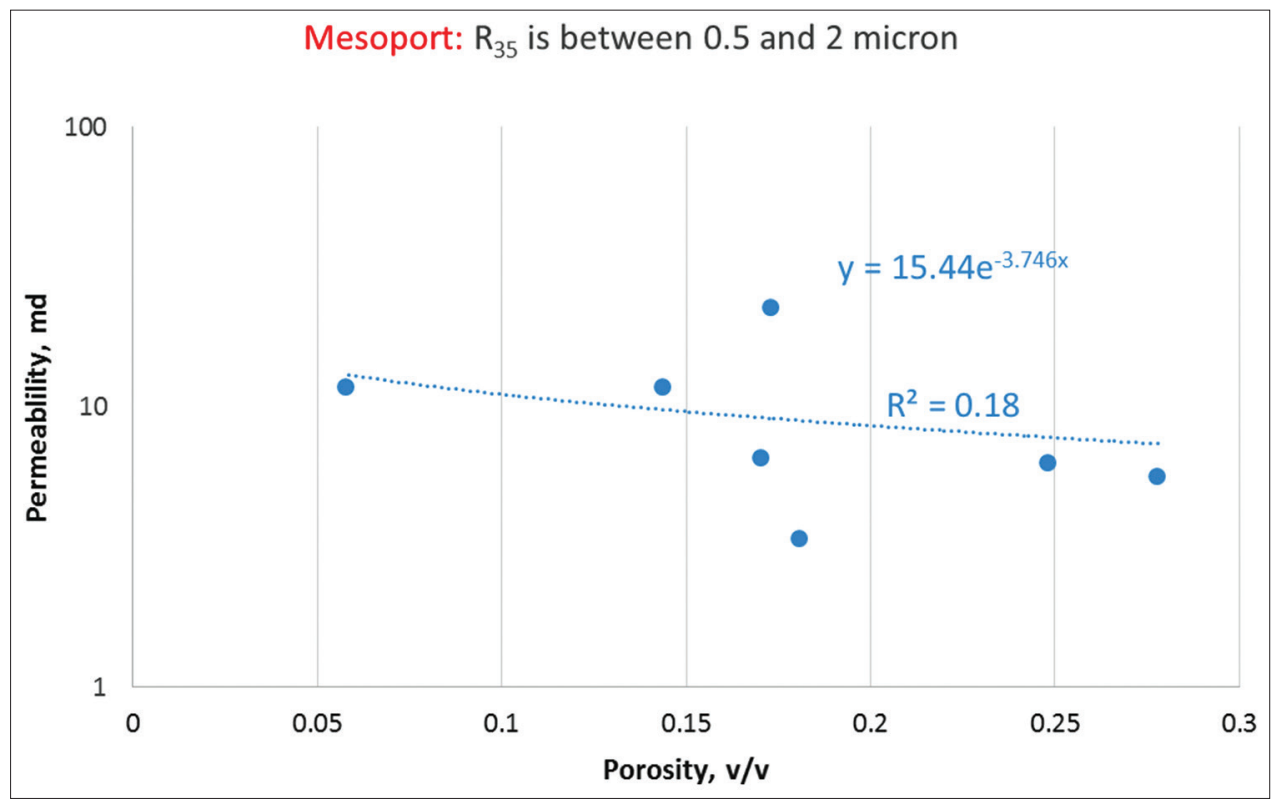

Fig. 5. Winland plot between porosity and permeability for well C

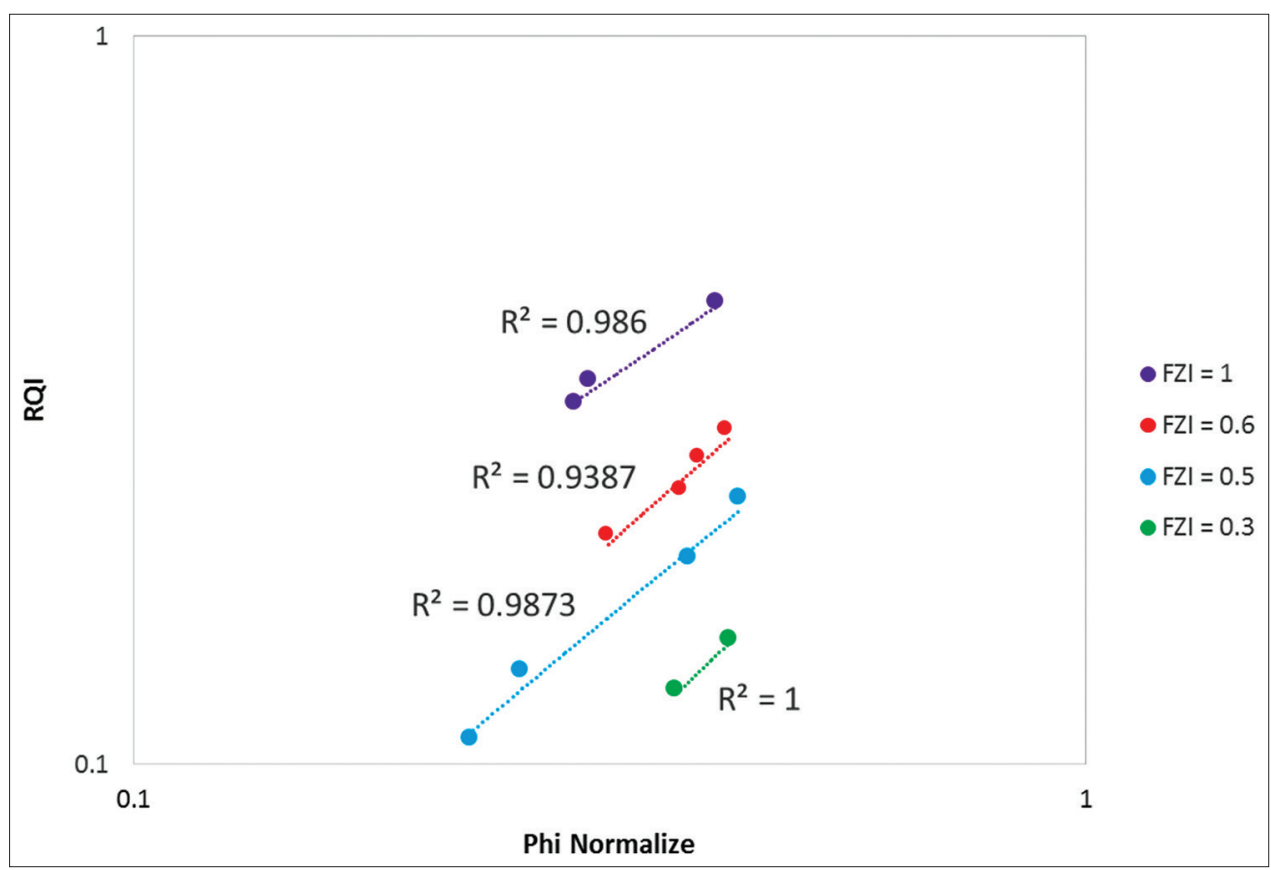

Fig. 6. Log-log plot of RQI versus $\varnothing z$ indicating the presence of four flow units for well $A$ 
Tariq Kaka Rash and Qays Mohammed Sadeq: Development Permeability prediction for Bai Hassan Cretaceous Carbonate Reservoir

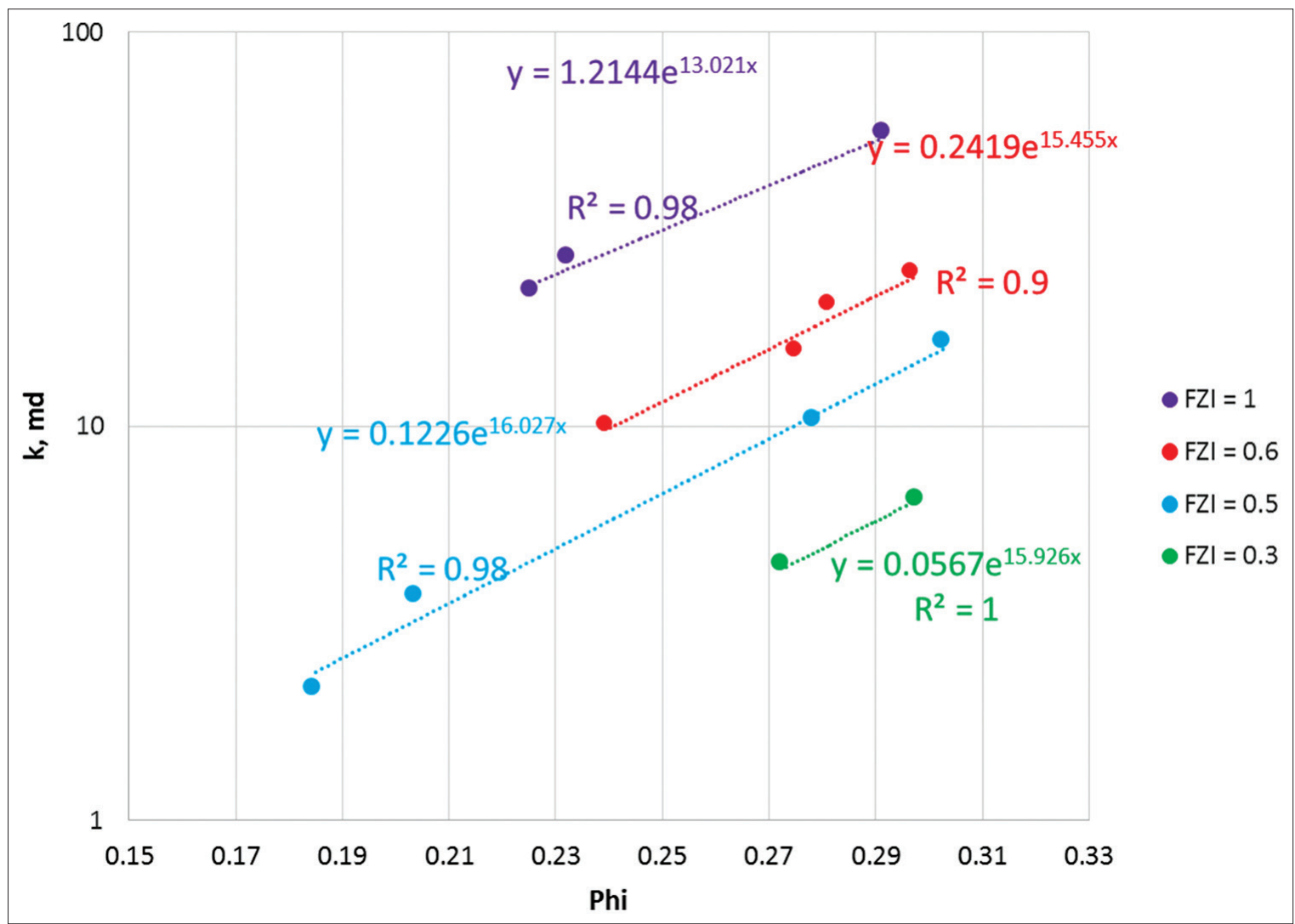

Fig. 7. Permeability porosity cross-plot for well A depending on FZI

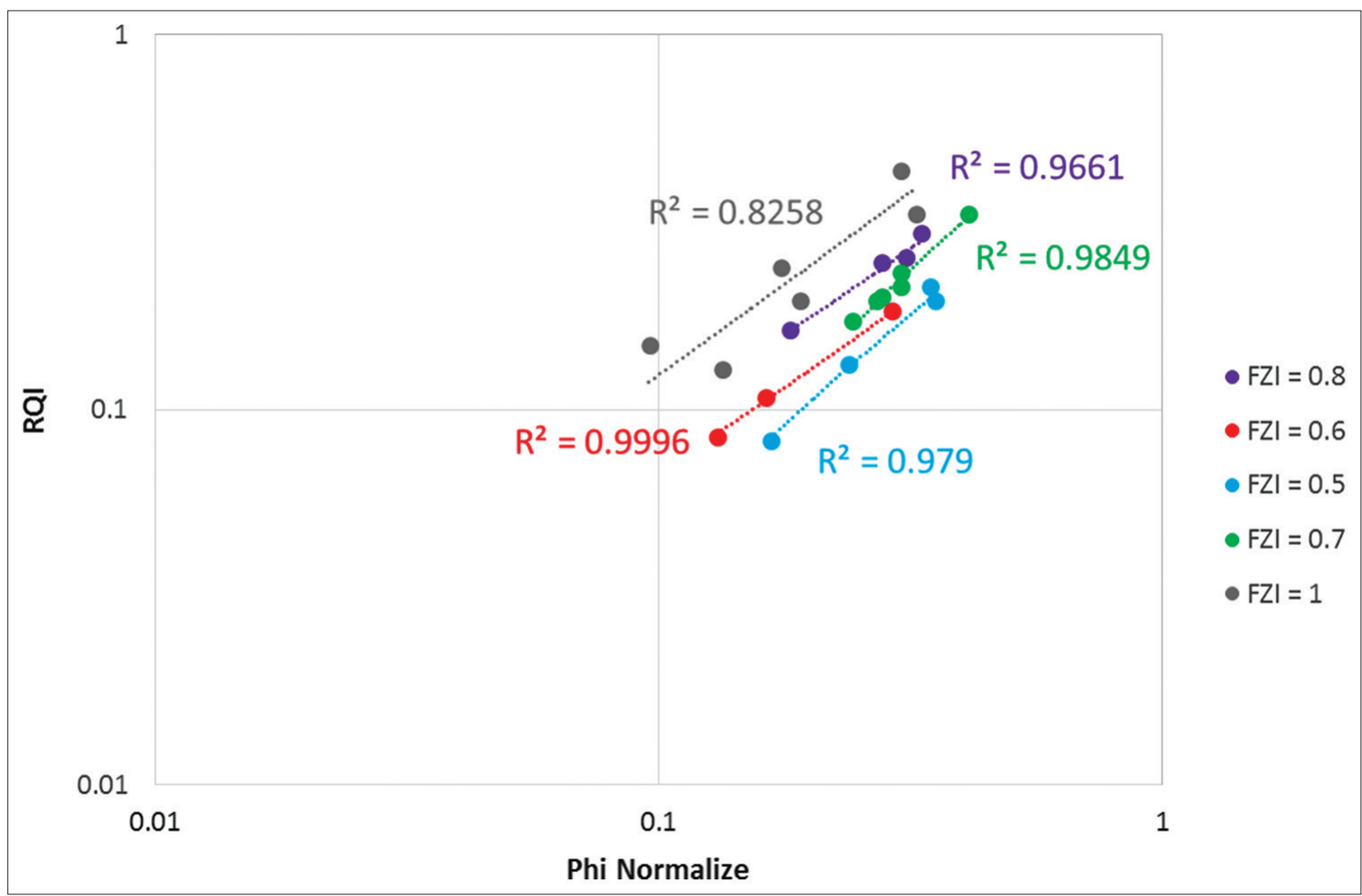

Fig. 8. Log-log plot of RQI versus Øz indicating the presence of five flow units for well $B$ 
Tariq Kaka Rash and Qays Mohammed Sadeq: Development Permeability prediction for Bai Hassan Cretaceous Carbonate Reservoir

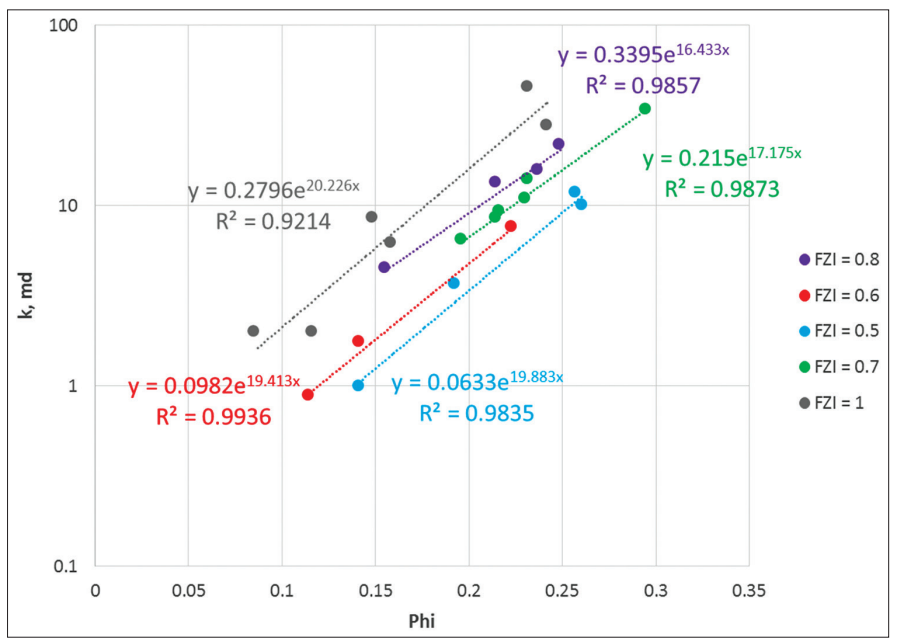

Fig. 9. Permeability porosity cross-plot for well B depending on FZI

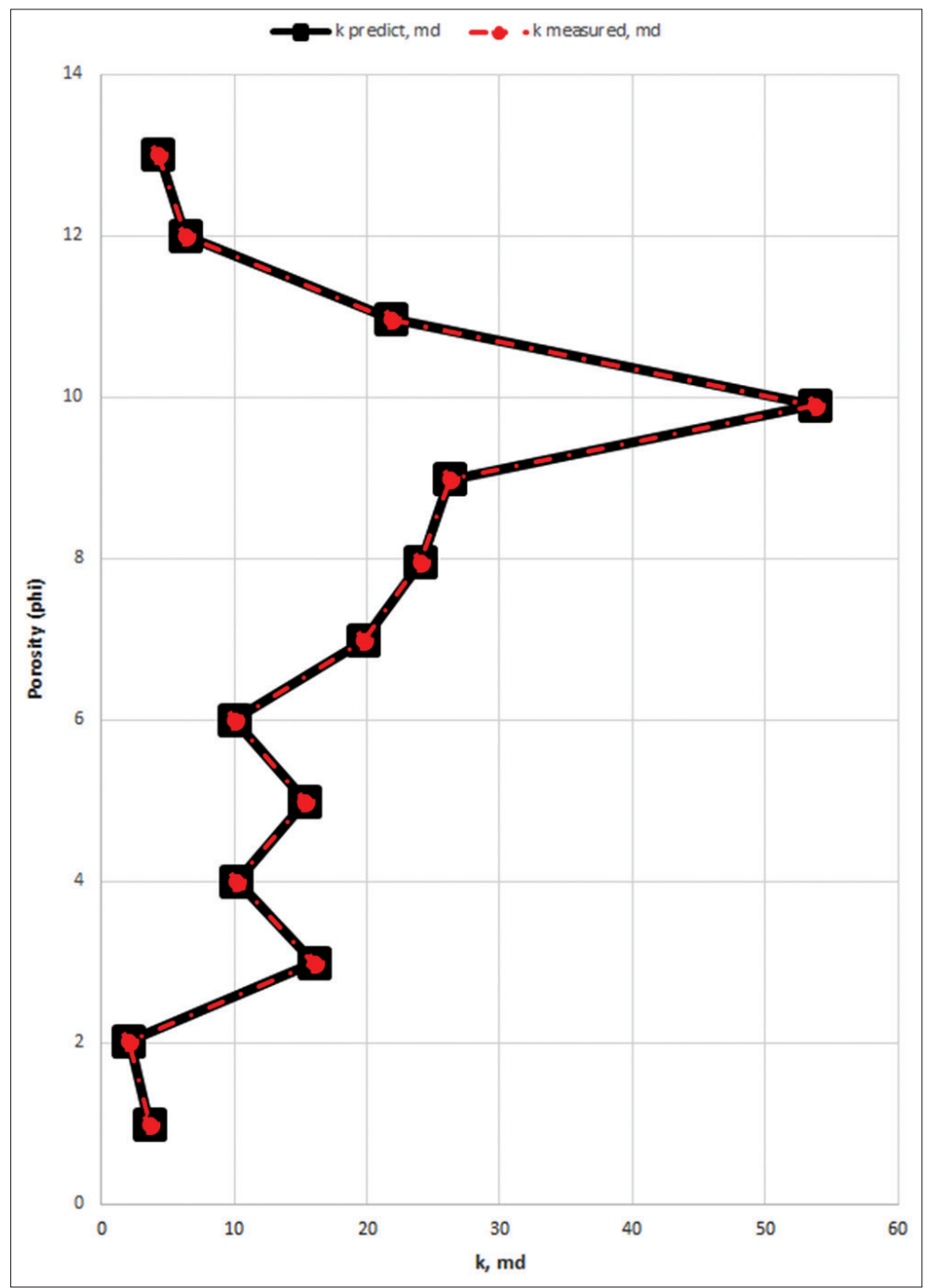

Fig. 10. Comparison between measured permeability and predicted permeability depending on Eq. (7) for well A shows excellent matching between a measured and predicted values, this represents that $V_{K}$ value is very close to zero, the reservoir is ideal homogeneous 


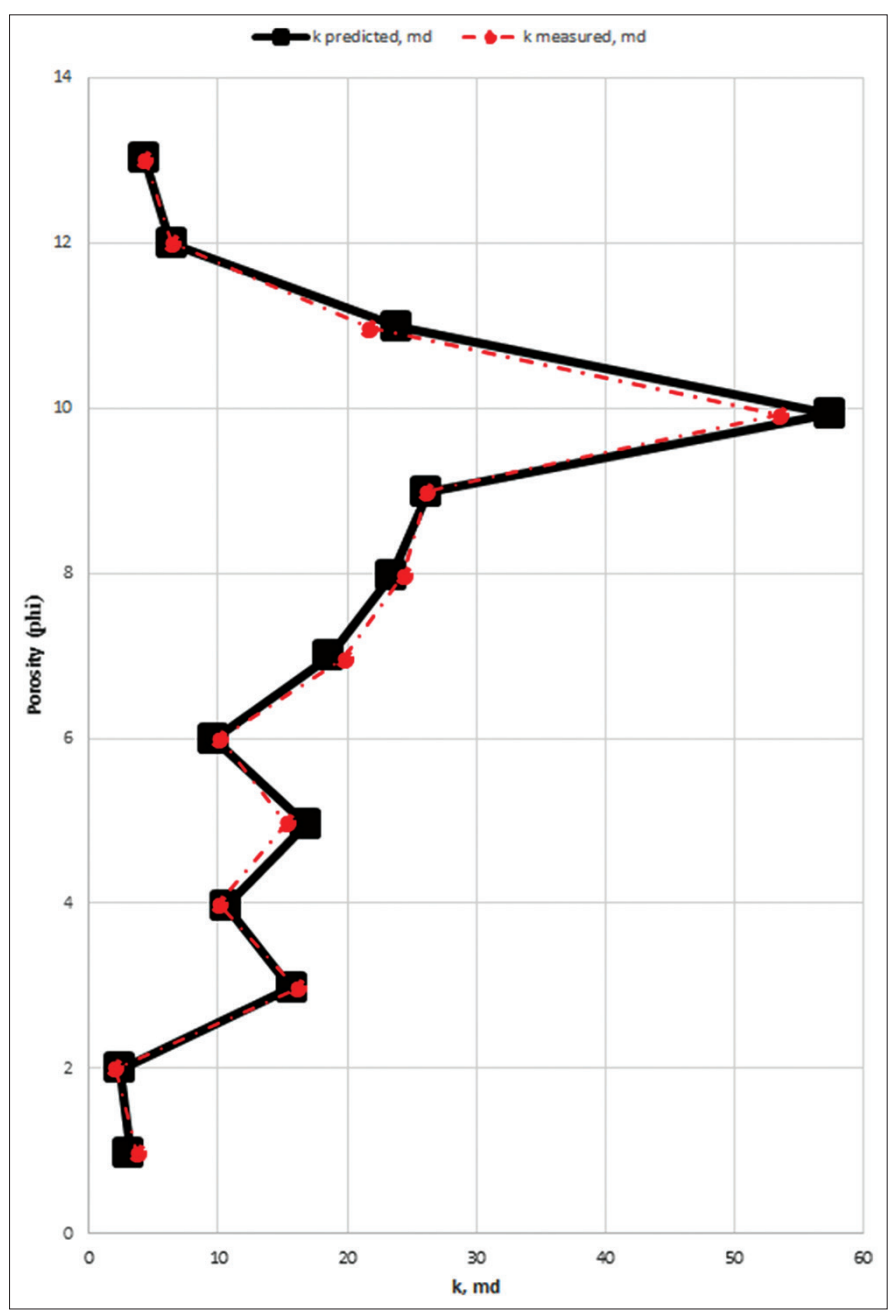

Fig. 11. Comparison between measured permeability and predicted permeability depending on $\mathrm{k}$ versus phi-dependent FZI for well A

$k=1014(F Z I)^{2} \frac{\emptyset_{e}^{3}}{\left(1-\varnothing_{e}\right)^{2}}$

Where, $\mathrm{k}$ is the permeability ( $\mathrm{md}), \varnothing e$ is the effective porosity (fraction), RQI is rock quality index $(\mu \mathrm{m}), \varnothing_{z}$ is the normalize porosity, and FZI is flow zone indicator. On a log-log plot of RQI versus $\varnothing_{z}$, all samples with similar FZI values will lie on other parallel lines. The values of FZI constant can be determined from the intercept of unit slope straight line at $\varnothing_{z}=1$, Haghighi et al. [13].

\section{CONCLUSION}

HFUM works perfectly to characterize and predict permeability for uncored wells as shown in Figs. 6, 8, and 14.

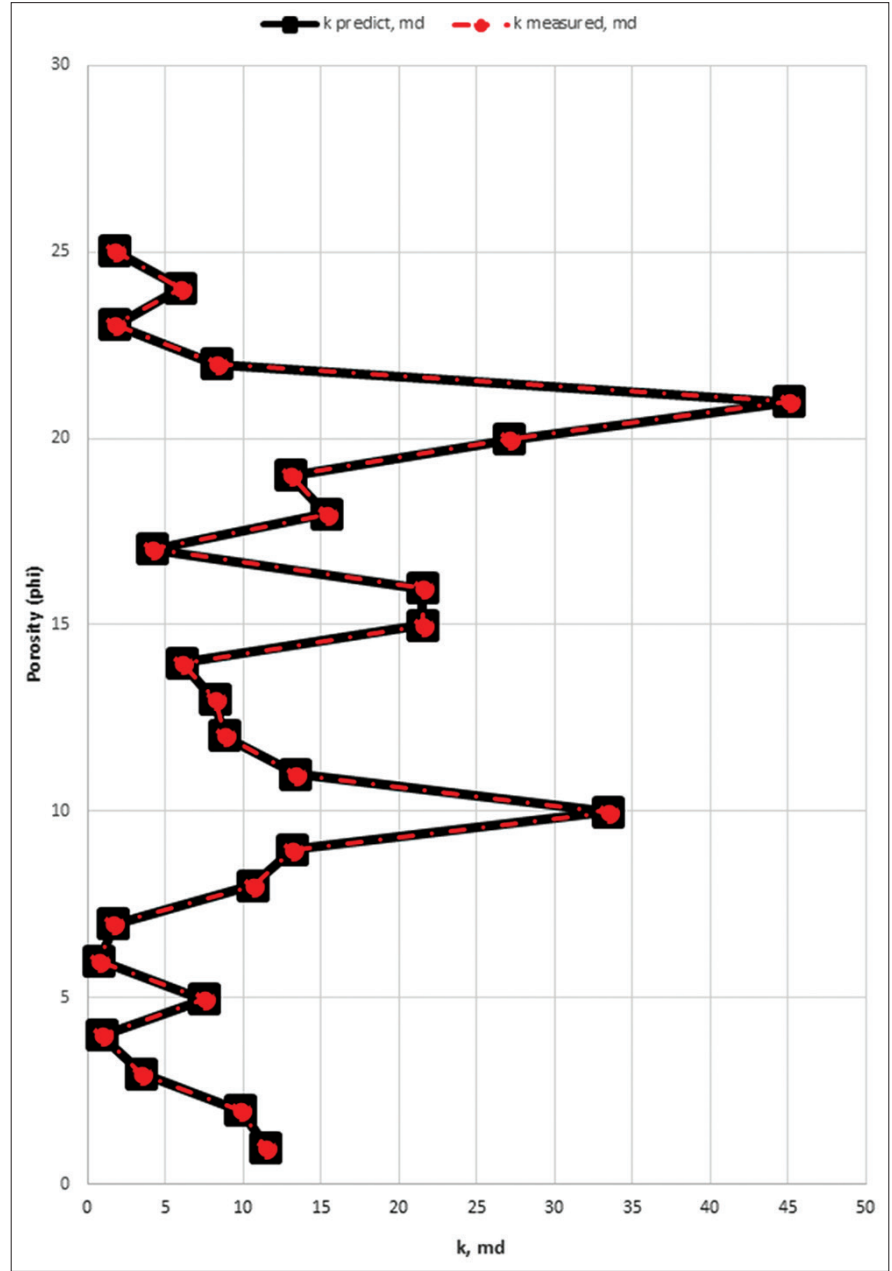

Fig. 12. Comparison between measured permeability and predicted permeability depending on Eq. (7) for well B shows excellent matching between a measured and predicted values, this represents that $V_{K}$ value is very close to zero, the reservoir is ideal homogeneous

They indicate that permeability can be accurately predicted from porosity if the rock type is known.

Porosity alone is not sufficient to describe the permeability variations, even if the porosity-permeability data that were used came from same field. This study shows good relationship between porosity and permeability depending on ZI as shown in Figs. 7-15.

The relationship is excellent because $R^{2} \approx 1$ and the presence of good matching between measured permeability and predicted permeability as shown in Figs. 11 and 13. The observations from this study refer to insignificant differences between porosity and permeability equations for each well alone and generalize equations (all three wells 
Tariq Kaka Rash and Qays Mohammed Sadeq: Development Permeability prediction for Bai Hassan Cretaceous Carbonate Reservoir

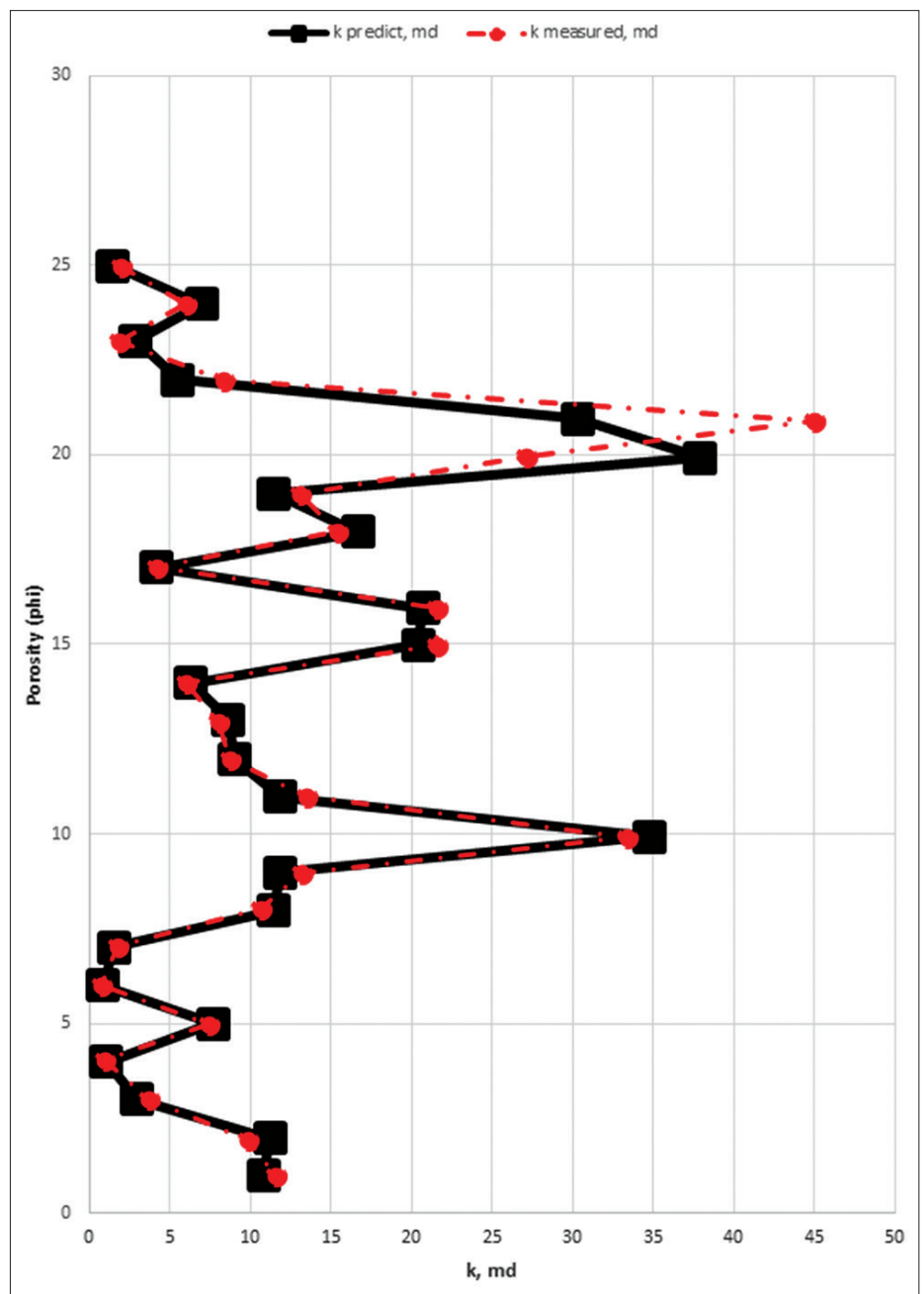

Fig. 13. Comparison between measured permeability and predicted permeability depending on k versus phi-dependent FZI for well B

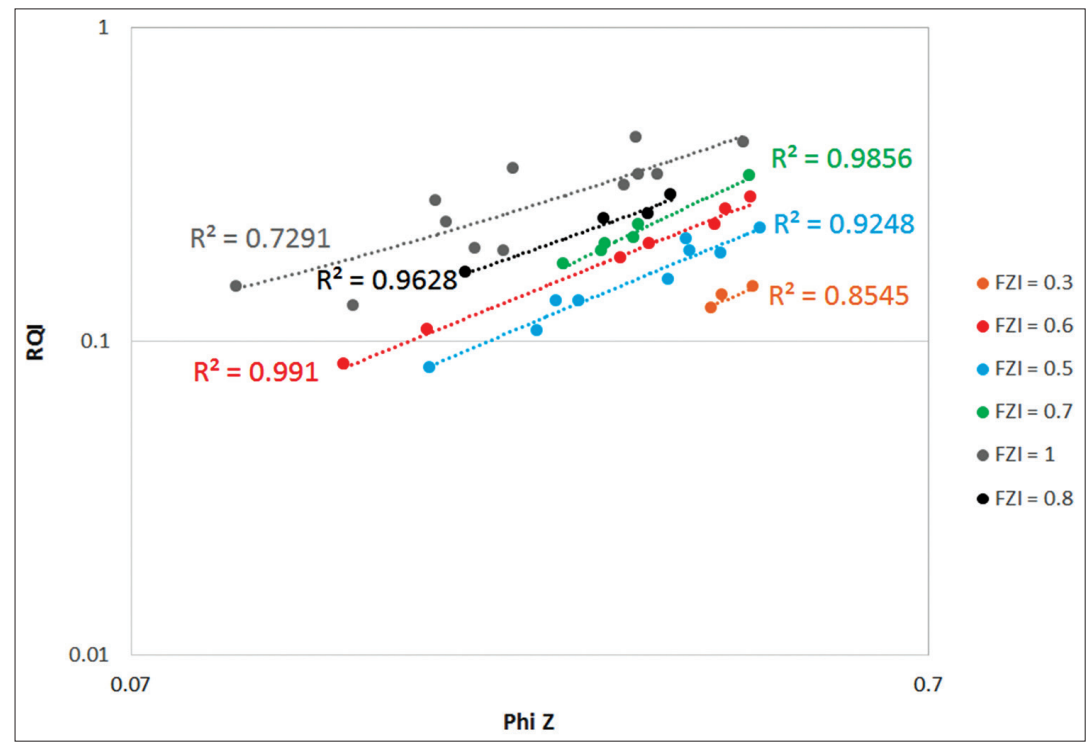

Fig. 14. Log-log plot of RQI versus Øz for the three studied wells 
Tariq Kaka Rash and Qays Mohammed Sadeq: Development Permeability prediction for Bai Hassan Cretaceous Carbonate Reservoir

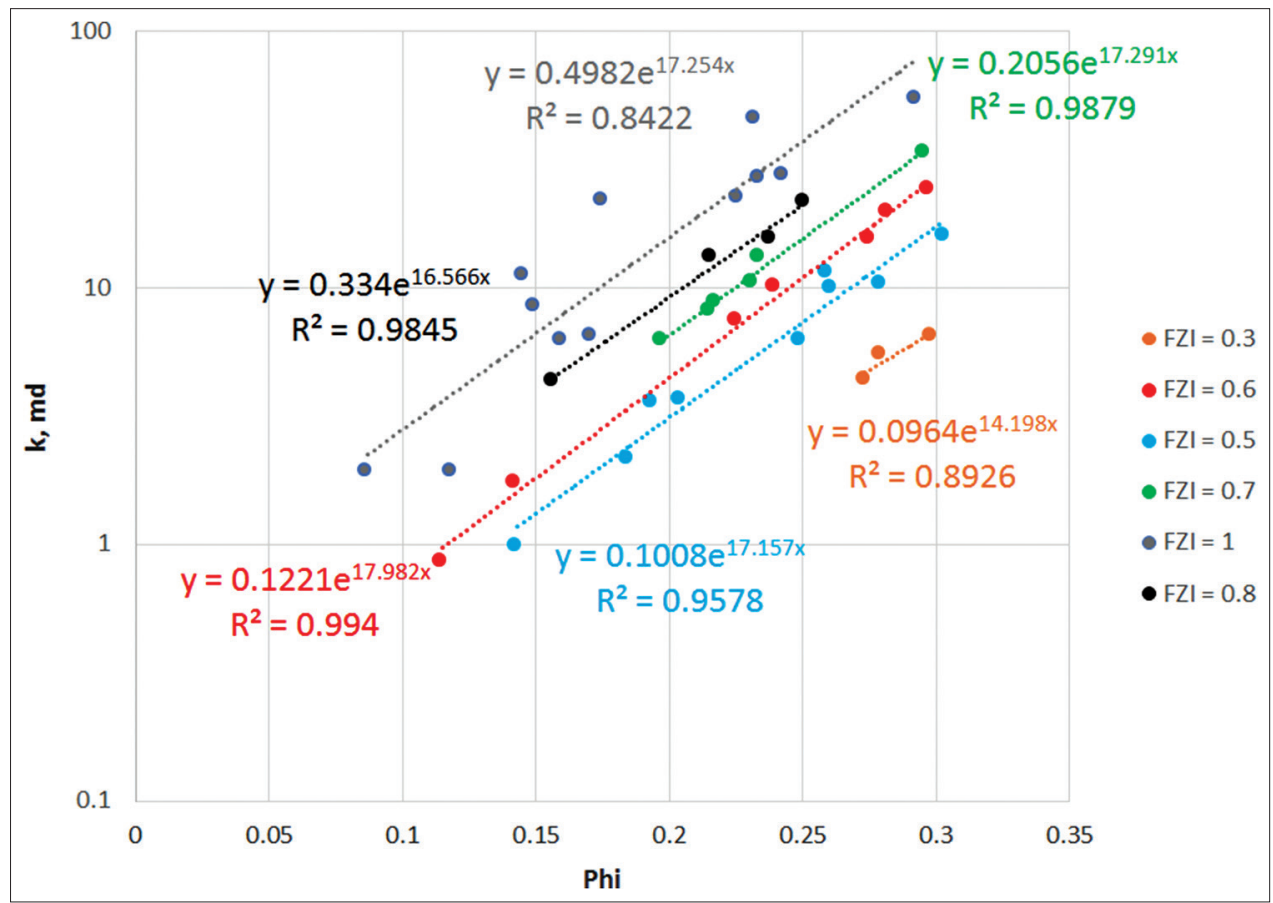

Fig. 15. Permeability porosity cross-plot for the three studied wells depending on FZI

\begin{tabular}{lccc}
\multicolumn{5}{c}{ TABLE I } \\
\multicolumn{4}{c}{ Generalized permeability depending on FZI } \\
\hline Well No & FZl & $\begin{array}{c}\text { Permeability Predicted from } \\
\text { Equations }\end{array}$ & $\boldsymbol{R}^{2}$ \\
\hline $\mathrm{A}$ & 0.3 & $\mathrm{k}=0.0567 \mathrm{e}^{15.926 \varnothing}$ & 1 \\
$\mathrm{~A}$ & 0.5 & $\mathrm{k}=0.1226 \mathrm{e}^{16.027} \varnothing$ & 0.9891 \\
$\mathrm{~A}$ & 0.6 & $\mathrm{k}=0.2419 \mathrm{e}^{15.455 \varnothing}$ & 0.971 \\
$\mathrm{~A}$ & 1 & $\mathrm{k}=1.2144 \mathrm{e}^{13.021 \varnothing}$ & 0.9869 \\
$\mathrm{~B}$ & 0.5 & $\mathrm{k}=0.0633 \mathrm{e}^{19.883 \varnothing}$ & 0.9835 \\
$\mathrm{~B}$ & 0.6 & $\mathrm{k}=0.0982 \mathrm{e}^{19.413 \varnothing}$ & 0.9936 \\
$\mathrm{~B}$ & 0.7 & $\mathrm{k}=0.215 \mathrm{e}^{17.175 \varnothing}$ & 0.9873 \\
$\mathrm{~B}$ & 0.8 & $\mathrm{k}=0.3395 \mathrm{e}^{16.433 \varnothing}$ & 0.9857 \\
$\mathrm{~B}$ & 1 & $\mathrm{k}=0.2796 \mathrm{e}^{20.226 \varnothing}$ & 0.9214 \\
$\mathrm{~A}, \mathrm{~B}$, and C & 0.3 & $\mathrm{k}=0.0964 \mathrm{e}^{14.198} \varnothing$ & 0.8926 \\
$\mathrm{~A}, \mathrm{~B}$, and C & 0.5 & $\mathrm{k}=0.1008 \mathrm{e}^{17.157 \varnothing}$ & 0.9578 \\
$\mathrm{~A}, \mathrm{~B}$, and C & 0.6 & $\mathrm{k}=0.1221 \mathrm{e}^{17.982 \varnothing}$ & 0.994 \\
$\mathrm{~A}, \mathrm{~B}$, and C & 0.7 & $\mathrm{k}=0.2056 \mathrm{e}^{17.291 \varnothing}$ & 0.9879 \\
$\mathrm{~A}, \mathrm{~B}$, and C & 0.8 & $\mathrm{k}=0.334 \mathrm{e}^{16.566 \varnothing}$ & 0.9845 \\
$\mathrm{~A}, \mathrm{~B}$, and C & 1 & $\mathrm{k}=0.4982 \mathrm{e}^{17.254 \varnothing}$ & 0.8422 \\
\hline
\end{tabular}

data). As shown in Table I, the high FZI values indicate high permeability values within four HFUs for well A and five for well B.

\section{REFERENCES}

[1] M. Qays. Heterogeneity, Connectivity and Geological Modeling of Tertiary Carbonate Reservoir in Bai Hassan Oil Field. Universiti
Teknologi PETRONAS, Northern Iraq, 2016.

[2] D. Tiab and E. C. Donaldson. Petrophysics: Theory and Practice of Measuring Reservoir Rock and Fluid Transport Properties. Gulf professional Publishing, USA, 2015.

[3] J. Kozeny. Über kapillare Leitung des Wassers im Boden:(Aufstieg, Versickerung und Anwendung auf die Bewässerung), HölderPichler-Tempsky, Wien, Austria, 1927.

[4] P.C. Carman. Permeability of saturated sands, soils and clays. The Journal of Agricultural Science, vol. 29, no. 02, pp. 262-273, 1939.

[5] A. Timur. An Investigation of Permeability, Porosity, and Residual Water Saturation Relationships, in Proceedings SPWLA 9 ${ }^{\text {th }}$ Annual Logging Symposium, Society of Petrophysicists and Well-Log Analysts, 1968.

[6] J.O. Amaefule, M. Altunbay, D. Tiab, D.G. Kersey and D.K. Keelan. Enhanced reservoir description: Using core and log data to identify hydraulic (flow) units and predict permeability in uncored intervals/ wells, in Proceedings SPE Annual Technical Conference and Exhibition, Society of Petroleum Engineers, Richardson, 1993.

[7] Q.M. Sadeq. Facies Analysis and Reservoir Modelling kf1 oil Field North of Iraq, 2010.

[8] Q. Sadeq and S. Bhattacharya. Permeability estimation of fractured and vuggy carbonate reservoir by permeability multiplier method in bai hassan oil Field Northern Iraq. Journal of Petroleum and Environmental Engineering, vol. 6, no.4, pp. 1-7, 2015.

[9] G. Gunter, J. Finneran, D. Hartmann and J. Miller. Early determination of reservoir flow units using an integrated petrophysical method, in Proceedings SPE Annual Technical Conference and Exhibition, Society of Petroleum Engineers, 1997.

[10] J. Bear. Dynamics of fluids in Porous Media: American. Else-vier, New York, 1972.

[11] Jr. W. Ebanks. Flow Unit Concept-Integrated Approach to Reservoir Description for Engineering Projects: AAPG (Am. Assoc. 
Tariq Kaka Rash and Qays Mohammed Sadeq: Development Permeability prediction for Bai Hassan Cretaceous Carbonate Reservoir

Pet. Geol.), Bull. (United States), vol. 71, no. CONF-870606, 1987.

[12] C. Hearn, Jr. W. Ebanks, R. Tye and V. Ranganathan. Geological factors influencing reservoir performance of the Hartzog Draw Field. Wyoming: Journal of Petroleum Technology, vol. 36, no. 08, pp. 1, 335-331, 344, 1984.
[13] M.B.P. Haghighi, M. Shabaninejad and K. Afsari. A Permeability Predictive model Based on Hydraulic Flow unit for one of Iranian Carbonate Tight gas Reservoir, in Proceedings SPE Middle East Unconventional Gas Conference and Exhibition, Society of Petroleum Engineers, 2011. 